ISSN 0258-7122 (Print), 2408-8293 (Online)

Bangladesh J. Agril. Res. 41(1): 183-194, March 2016

\title{
EFFECT OF VARIOUS CEREALS ON THE DEVELOPMENT OF CORCYRA CEPHALONICA (STAINTON) AND ITS EGG PARASITOID TRICHOGRAMMA CHILONIS (ISHII)
}

\author{
M. NASRIN ${ }^{1}$, M. Z. ALAM ${ }^{2}$, S. N. ALAM ${ }^{3}$ \\ M. R. U. MIAH ${ }^{4}$ AND M. M. HOSSAIN ${ }^{5}$
}

\begin{abstract}
Eight types of cereals viz., wheat grain, chopped wheat, paddy grain, rice grain, maize grain, chopped maize, rice bran, mixture of rice bran and chopped rice were fed to observe the development parameters like egg, larva, pupa and adult stages of Corcyra cephalonica (stainton) for three consecutive generations. The parasitism efficiency of Trichogramma chilonis (Ishii) was also evaluated on the resultant host eggs of $C$. cephalonica. The $C$. cephalonica revealed the highest number of eggs (115.6 female $\left.{ }^{1}\right)$, higher hatchability (92.9\%), extented larval duration (45.9 days), increased larval weight ( $0.058 \mathrm{gm})$, survival rate $(88.3 \%)$, adult emergence rate $(93.5 \%)$, and male and female longevity $(7.7,7.2$ days respectively) when they were reared on chopped wheat. On the other hand, the lowest number of egg was found on paddy husk $\left(29.2\right.$ female $\left.^{-1}\right)$. The lowest hatchability (45.6\%), larval duration (45.9 days), larval weight $(0.029 \mathrm{gm})$, and survival rate (38.2\%), pupal duration (17.9 days) adult emergence (42.0\%), male and female longevity (4.8 and 4.7 days respectively) were found on paddy husk. The effect of food materials also reflected on the parasitism efficiency of the egg parasitoid $T$. chilonis. The highest percent egg parasitization was done by the $T$. chilonis on the host eggs, reared on chopped wheat $(94.8 \pm 0.07 \%)$ followed by wheat grain $(82.5 \pm 0.08 \%)$ and chopped maize $(73.8 \pm 0.09 \%)$. On the other hand, the lowest parasitism was obtained when the larvae were reared on paddy husk $(42.2 \pm 0.14 \%)$ and paddy grain $(48.8 \pm 0.05 \%)$.
\end{abstract}

Keywords: Cereals, C. cephalonica, development, parasitism, $T$. chilonis.

\section{Introduction}

There are many biological control agents such as predators, parasitoids and microorganisms, which are naturally controlling the insect pests (Bhandari, 2014). Among them, parasitoids have a major role in agricultural ecosystem. Of the effective bio-control agents, the egg parasitoid, Trichogramma is considered as the most important, particularly for augmentation. But, the number of eggs destroyed by natural Trichogramma is not sufficient to combat the pest from reaching the economic threshold level. So, its mass rearing and release for augmentation is vital.

${ }^{1,2 \& 4}$ Dept. of Entomology, Bangabandhu Sheikh Mujibur Rahman Agricultural University (BSMRAU), Gazipur-1706, ${ }^{3}$ Entomology Division, Bangladesh Agricultural Research Institute (BARI), Gazipur-1701, ${ }^{5}$ Dept. of Horticulture, BSMRAU, Gazipur-1706, Bangladesh. 
Mass rearing of Trichogramma requires the rearing of its host. The typically rearing of a species of moth can produce enough eggs on which the wasps may be developed. The rice meal moth, Corcyra cephalonica (stainton) and the Mediterranean flour moth Ephestia kuehniella Zeller are easily and inexpensively reared on wheat, rice or other cereals and their eggs are commonly used to rear Trichogramma (Morrison et al., 1976). They also advocated to mass rear Sitotroga cerealella (Olivier) to provide eggs for Trichogramma rearing.

The $C$. cephalonica is popularly known as "rice moth". It is distributed worldwide and a serious pest of stored husked and unhusked rice, other cereals and leguminous grains. It also attacks gingelly, oil-cakes, dry fruits, cocoa, chocolates, biscuits, flax seeds, cream of wheat, flour etc. in many countries of the world (Perveen, 2012). The larvae damage the stored grains by feeding under silken webs (Alam, 1971). When infestation is high, the entire stock of grains may be converted into a webbed mass and ultimately a characteristic bad smell develops and the grains are rendered unfit for human consumption (Alam, 1965). Besides, many damaging properties of $C$. cephalonica and its eggs serve as an important medium for the successful breeding and rearing of Ttichogramma spp. which are used for biological control programme of different destructive borers in many countries of the world (Chu et al., 1994; Mukhukrishnan et al,. 1996; Cadapan, 1998). Due to the unavailability of egg masses of different borers throughout the year for mass production of T. chilonis, sufficient numbers of $C$. cephalonica eggs are essential. All the activities in life are dependent on the type and quality of food material of an individual. Andrewartha and Birch (1954) stated that both the longevity and reproductive potential of insects were influenced by the components of the environment, including temperature, moisture, and food. A considerable amount of information on various aspects of Corcyra are available. Rearing of these moths is generally done on wheat or chopped rice in the laboratory. However, the cost of rearing of rice moth on wheat or chopped rice is considerably high (Avasthy, 1962). As a result, the commercial productions of the parasitoid, Trchogramma spp. from their eggs also become costly. So, it is very much necessary to select some cheaper and cost effective food material(s) which can ensure proper development of $C$. cephalonica and production of its significant number of eggs for successful rearing of the egg parasitoid, Trichogramma spp.

\section{Materials and Methods}

This study was carried out in the IPM laboratory of the Entomology Division, Bangladesh Agricultural Research Institute, Joydebpur, Gazipur during July 2008 and May 2009. 


\section{Stock culture of $C$. cephalonica}

For constant supply of test insects and to avoid the effect of previous food, separate stock cultures of C. cephalonica were used. Five $\mathrm{kg}$ of wheat poured into boiled water and left for 2-3 minutes. Then the treated wheat was kept in steel trays (50 $\mathrm{cm} \times 60 \mathrm{~cm}$ ), each tray containing $2.5 \mathrm{~kg}$ wheat and $1 \mathrm{gm} \mathrm{C}$. cephalonica egg and kept for 5-6 days untouched. After that requisite quantity of water was added and mixed properly with gentle stirring. After 22-25 days, C. cephalonica infested wheat was placed in mass rearing chamber for adult emergence. From the insect mass rearing chamber $C$. cephalonica adults were collected for two studies.

\section{Determination of the cost effective food materials}

Eight types of cereals : wheat grain, chopped wheat, paddy grain, rice grain, maize grain, chopped maize, rice bran, and mixture of rice bran and chopped rice were taken in separate plastic pots (500 gm for each) after sterilization. In each pot, 50 eggs of $C$. cephalonica were spread over on 500 gm cereals and kept in ambiant temperature of $26.0 \pm 2.0{ }^{\circ} \mathrm{C}$ in the laboratory. The mouths of the pots were covered with mosquito net. The pots were checked regularly to observe larval emergence, growth period, duration of pupa and adult. Each plastic pot containing host insect with a single cereal was considered as one treatment replication. There were three replications per treatment and the experiment was set in completely randomized design. Data on the duration of different development parameters viz., egg, larva, pupa and adult stages were measured for consecutive three generations.

\section{Determination of economic host for egg parasitoid, $T$. chilonis}

Eggs were collected from the reared moth population grown on different cereals and these were parasitized by egg parasitoid in the following means: Paper strips with host eggs were made to use them in the present study. For making the egg strips the material like, i) paper strip $(10 \mathrm{~cm} \times 1 \mathrm{~cm})$ with different colours (yellow, red, blue ) and labeling, ii) acacia powder of Acacia arabica (LAM), iii) distilled water, iv) small petri dish, and v) dropper are required. At first $10 \%$ acacia gum was prepared in a small petri dish by mixing acacia powder and distilled water. Mixing of water was done with dropper to maintain the proper dilution of the gum to hold the host eggs firmly with the paper strips. To make the host egg strips, a small amount of acacia glue was taken by finger and smeared on the front side of the labeled paper strip. Previously counted 100 eggs were placed carefully on the glued portion of the paper strip to have a single layer of eggs on the strips. After preparing the strips, it was labeled with date, host name, parasitoid name and number of eggs per strip. 
The parasitism efficacy of $T$. chilonis was evaluated on the resultant host eggs of C. cephalonica. For the parasitization, one host egg strip, containing 100 eggs of the host and one $T$. chilonis pupae strip were placed together in individual test tube. Strips with $T$. chilonis pupae ready to emerge were taken from the already reared colony of $T$. chilonis. A strip containing 100 pupae of Trichogramma / strip of $C$. cephalonica eggs were placed in the test tube. The test tubes, each containing one host egg strip and one $T$. chilonis pupae strip were then placed in the parasitization chamber after proper labeling with date, number of eggs, host name and parasitoid name.

In the parasitization chamber, two third portions of the test tubes were covered by black cloths except the eggs which were placed for the parasitization to provide enough light for frequent movement of Trichogramma.

\section{Data collection}

Data on parasitism efficacy of $T$. chilonis attacking resultant host eggs of $C$. cephalonica deposited on different cereals were collected. Percent egg parasitism and percent emergence of $T$. chilonis were calculated.

\section{Statistical analysis}

Data were analysed by following MSTAT-C program. The mean values were separated by DMRT test $(\mathrm{p}<0.05)$.

\section{Results and Discussion}

There was significant difference in the number of eggs per female when fed on different cereals (Table 1). Considering the mean of three generations, the highest eggs were laid per female when their larvae fed on chopped wheat (115.6), chopped maize (62.2), and maize grain (52.2) (Table 1). On the other hand, the lowest eggs were laid per female when larvae reared on paddy grain (37.9) and paddy husk (29.2) (Table 1). It indicates that the paddy is the most non preferred host. This was probably due to the presence of trichome on the rice grain surface which restrains the female moths to lay their eggs. Acevedo and Aviles (1985) obtained higher number of larvae from polished grains compared to unpolished ones.

The highest incubation period was observed when larvae of $C$. cephalonica reared on paddy husk (5.8 days) and this was followed by paddy grain (4.5 days), maize grain (4.4 days), chopped maize (4.2 days) etc. However, the lowest incubation period was observed in chopped wheat (2.8 days), which was significantly different from that of rice grain (3.5 days) (Table 1). Therefore, the food quality also affects the incubation of eggs. The poorest quality food materials may prolong incubation period, while the best quality food reduces the incubation period. Mbata (1989) indicated that development of C. cephalonica on quality food (broken and meal maize) shortened the incubation and larval period. 


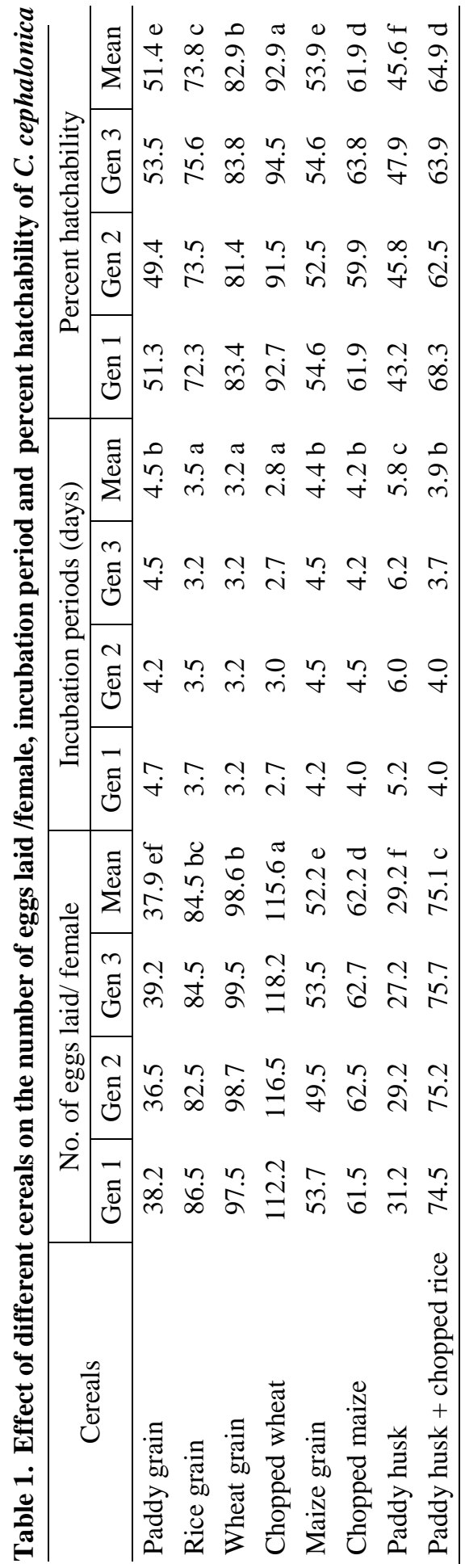


The highest percent hatchability was observed among eggs on the chopped wheat (92.9) which was significantly higher than that of the others. However, the lowest percent hatchability was observed in paddy husk (45.6) and paddy grain (51.4). Hatchability might be increased by the good quality of food as indicated by Mbata (1989).

\section{Gen $=$ Generation}

\section{Means followed by the same letter(s) in a column did not differ significantly (DMRT test; $\mathbf{p}=\mathbf{0 . 0 5}$ )}

Table 2 shows that the larval duration was the highest on paddy husk (45.9 days) and paddy grain (41.3 days). On the other hand, larval duration was significantly the lowest on chopped wheat (23.5 days) followed by wheat grain (26.1 days), rice grain (29.8 days), paddy husk and chopped rice (33.5 days), chopped maize (36.4 days) and maize grain (40.9 days) (Table 2). Qualities of food also have a significant effect on the larval growth. Larval duration of $C$. cephalonica was studied by several authors and it was revealed that the larval duration in sorghum lasted for 45.56 days with a maximum of 111 days (Ayyar, 1934). Seshagiri (1954) reported larval duration of 47.57 days on cereals and 46-60 days on pulses. Alam (1965) observed the period with a range of 23-25 days on wheat, but sometime it may be extended up to 55 days.

The highest weight was gained when the larva fed on the preferred food materials, chopped wheat $(0.058 \mathrm{gm})$, and this was followed by wheat grain $(0.052 \mathrm{gm})$, rice grain $(0.042 \mathrm{gm})$, paddy husk and chopped rice $(0.040 \mathrm{gm})$, chopped maize $(0.037$ $\mathrm{gm})$, maize grain $(0.030 \mathrm{gm})$ (Table 2$)$. On the other hand, the lowest weight was obtained when the larvae were reared on paddy grain $(0.029 \mathrm{gm})$ and paddy husk (0.031 gm)

Survival of larva was also depended on the quality of food materials. Due to quality of food, larval survival rate became higher as compared to low quality of food. The highest percentage of larval survival was observed in chopped wheat $(88.3 \%)$ and the lowest in paddy husk (38.2\%) with significant difference (Table 2). The higher larval weight and its survival may also be influenced by the preferred food with high quality as reported by Mbata, 1989 and Ray, 1994.

\section{Gen $=$ Generation}

\section{Means followed by the same letter ( $s$ ) in a column did not differ significantly (DMRT test; $\mathbf{p}=\mathbf{0 . 0 5}$ )}

The pupal duration was also significantly affected by the qualities of food materials used for rearing C. cephalonica (Table 3). The lowest pupal period was observed when chopped wheat was utilized as food (9.1 days) followed by wheat grain (9.5 


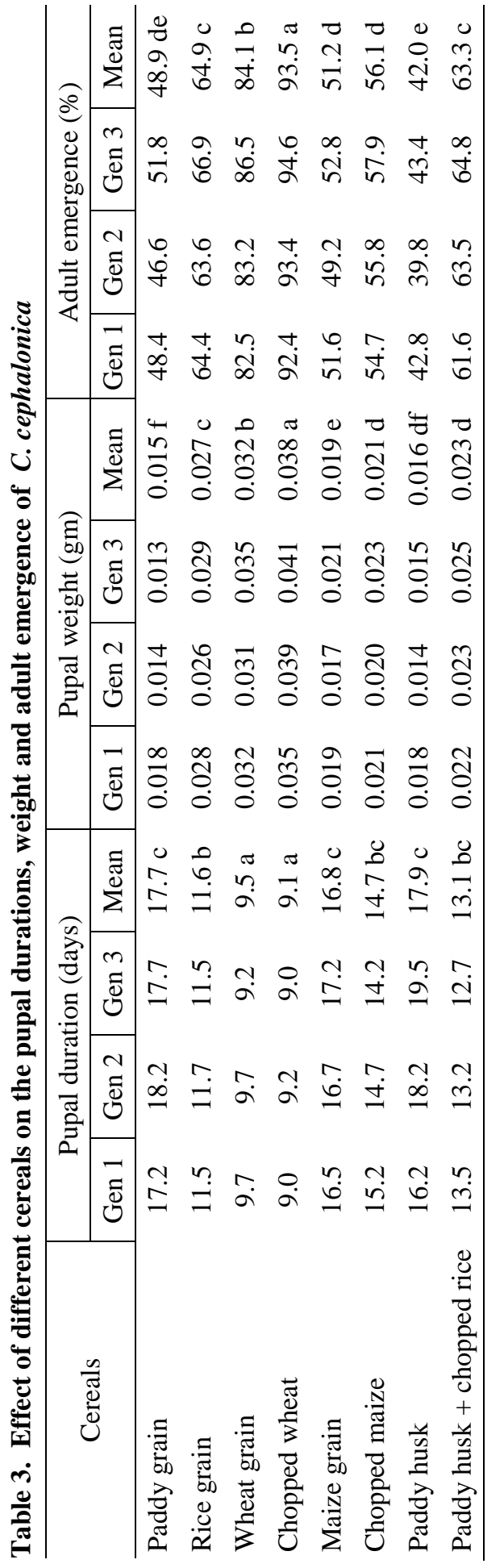


days), rice grain (11.6 days), paddy husk and chopped rice (13.1 days), chopped maize (14.7 days), maize grain (16.8 days). On the other hand, the highest duration was required for pupa to became adult when the larva was reared on paddy grain (17.7 days) and paddy husk (17.9 days). Ayyar (1934) observed pupal period of 12 days when cultured on sorghum, Nicol (1935) obtained a pupal period of 10 days when grown on wheat grains. On the other hand, Alam (1965) observed 10 days pupal period when reared on stored wheat.

The highest pupal weight was gained by the pupa when its larva was fed on the preferred food materials, chopped wheat $(0.038 \mathrm{gm})$, followed by those grown on wheat grain $(0.032 \mathrm{gm})$, rice grain $(0.027 \mathrm{gm})$, paddy husk, chopped rice $(0.023$ $\mathrm{gm})$, chopped maize $(0.021 \mathrm{gm})$, maize grain $(0.019 \mathrm{gm})$ (Table 3$)$. On the other hand, the lowest pupal weight was obtained

when the larvae were reared on paddy grain $(0.015 \mathrm{gm})$ and paddy husk $(0.016$ gm). Like pupal duration, pupal weight was also affected positively by the preferred food with better quality (Ayyar, 1934; Nicol, 1935).

The highest numbers of adult were emerged from the pupae when their larvae were reared on chopped wheat (93.5\%) and the pupal weight recorded in this food material was also the highest. The similar trend was followed in other food materials. The lowest adult emergence was recorded from the paddy grain $(48.9 \%)$ and paddy husk $(42.0 \%)$.

\section{Gen $=$ Generation}

\section{Means followed by the same letter ( $s$ ) in a column did not differ significantly (DMRT test; $\mathbf{p}=\mathbf{0 . 0 5}$ )}

The highest longevity of male moth was 7.7 days when their larvae grown on chopped wheat followed by 7.1 days when fed on wheat grain, 6.6 days on rice grain, 6.4 days in paddy husk and chopped rice, 6.2 days in chopped maize and 5.5 days on maize grain (Table 4). On the other hand, the lowest longevity of male moth was recorded when the larvae were reared on paddy grain (5.4 days) and paddy husk (4.8 days). Similar trend of female longevity was also recorded due to qualitative difference of various cereals used during its development. The highest longevity of female moths was found 7.2 days when larvae grown on the chopped wheat while the lowest was 4.7 days on paddy husk. (Ozpnar, 1997)

The lowest life span was evident when larvae fed on chopped wheat (43.1 days) while the highest on paddy husk (74.5 days) (Table 4). It was 45.9 days when larvae grown on wheat grain, but it was 51.4 days on rice grain, 56.5 days in paddy husk + chopped rice , 67.7 days on maize grain, 61.6 days on chopped maize and 


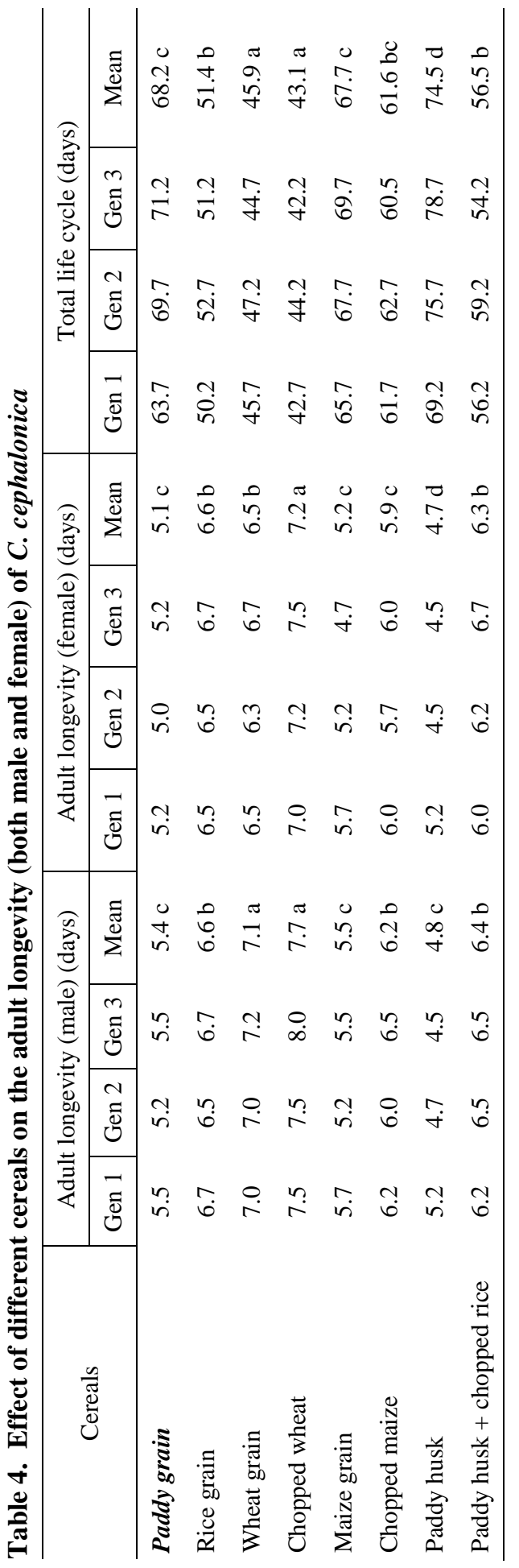


68.2 days on paddy grain. The adult longevity of both male and female moths and the total life span were influenced by the quality of food. Better quality food increased the longevity of both male and female moths but shorten the total life span of $C$. cephalonica as reported by Devaraj and Mukherjee (1966) when they reared $C$. cephalonica on groundnut and sesame. They found groundnut was superior than sesame qualitatively. Total life span of 61.42 days in groundnut while 76.89 days in sesame was recorded by them. On the other hand, the highest longevity of female moths ( 7.2 days) was observed when larvae fed on the chopped wheat and the lowest (4.7 days) was on paddy husk.

\section{Gen $=$ Generation}

\section{Means followed by the same letter (s) in a column did not differ significantly (DMRT test; $\mathbf{p}=\mathbf{0 . 0 5}$ )}

The highest percent egg parasitization $(94.8 \pm 0.07 \%)$ was on chopped wheat followed by those reared on wheat grain $(82.5 \pm 0.08 \%)$, chopped maize $(73.8 \pm 0.09 \%)$, rice grain $(67.8 \pm 0.11 \%)$, paddy husk and chopped rice $(66.8 \pm 0.09$ $\%)$, maize grain $(59.8 \pm 0.13 \%)$. On the other hand, the lowest parasitism was obtained when the larvae were reared on paddy husk $(42.2 \pm 0.14 \%)$ and paddy grain (48.8 \pm 0.05$)$.

Table 5. Parasitism efficacy of T. chilonis on C. cephalonica eggs reared on different cereals

\begin{tabular}{l|l|l}
\hline \multicolumn{1}{c}{ Cereals } & Percent egg parasitism * & Percent adult parasitoid emergence * \\
\hline Paddy grain & $48.8 \pm 0.05 \mathrm{f}$ & $37.5 \pm 0.13 \mathrm{~d}$ \\
Rice grain & $67.8 \pm 0.11 \mathrm{~d}$ & $78.6 \pm 0.09 \mathrm{c}$ \\
Wheat grain & $82.5 \pm 0.08 \mathrm{~b}$ & $88.7 \pm 0.18 \mathrm{~b}$ \\
Chopped wheat & $94.8 \pm 0.07 \mathrm{a}$ & $98.6 \pm 0.07 \mathrm{a}$ \\
Maize grain & $59.8 \pm 0.13 \mathrm{e}$ & $76.6 \pm 0.19 \mathrm{c}$ \\
Chopped maize & $73.8 \pm 0.09 \mathrm{c}$ & $87.9 \pm 0.11 \mathrm{~b}$ \\
Paddy husk & $42.2 \pm 0.14 \mathrm{f}$ & $32.2 \pm 0.17 \mathrm{~d}$ \\
$\begin{array}{l}\text { Paddy husk }+ \\
\text { chopped rice }\end{array}$ & $66.8 \pm 0.09 \mathrm{~d}$ & $77.8 \pm 0.10 \mathrm{c}$ \\
\hline
\end{tabular}

\pm Standard Error; means followed by the same letter (s) did not differ significantly by DMRT $(\mathrm{p}<0.05)$.

* Analysis was done after square root transformation.

Like percent egg parasitism, percent adult parasitoid emergence also differed among the food items (Table 5). The variations of egg parasitism and adult 
parasitoids emergence from the parasitised eggs may be due to the quality of the food materials. The present study revealed that chopped wheat was the most preferred food. On the other hand, both paddy grain and paddy husk were the most non-preferred food items and these might be poor in quality for development of host eggs, which in turns invited less number of parasitoids female than the most preferred quality food like chopped wheat.

\section{References}

Acevedo, R. and R. Aviles. 1985. Ability of Corcyra cephalonica (Galleriidae: Lepidoptera) to infest stored rice. Rev. Appl. Ent. 73(1): 50.

Alam, M.Z. 1965. Insect Pests of Rice in East Pakistan and their Control (Rev. ed.). Agric. Inf. Serv., 3, R.K. Mission Road, Dacca-3, P. 62.

Alam, M. Z. 1971. Pests of Stored Grain and other Stored Products and their Control. Agric Inf. Serv., 3, R.K. Mission Road, Dacca-3, Pp. 23-24.

Andrewartha, H. G. and L. C. Birch, 1954. The Distribution and Abundance of Animals. The University of Chicago Press. Pp. 31-205.

Avasthy, P.N. 1962. Biological control of the insect pest of sugarcane. Indian sugar 12: 345-358.

Ayyar, P.N.K. 1934. A very destructive pest of stored products in South India, Corcyra cephalonica (Stain.). Bull. Ent. Res. 25(2): 155-169.

Bhandari, G. 2014. Effect of different diets on biology of Corcyra cephalonica, ijasbt.org/vol-2/Bhandari - et al. - 2.4. pdf.

Cadapan, E.P. 1998. Trichogramma mass production in the Philippines. Rev.Appl. Ent. 77(5): 343

Chu-Yaui, Tu-Menping and Cheng-Wenyi. 1994. Effect of photoperiodism on the larval development, adult emergence and fecundity of the rice moth, Corcyra cephalonica (Stain.) (Galleriidae: Lepidoptera) at constant temperature. Ent. Abst. 25(6): 74 .

Devaraj, K.C. and P.B. Mookherjee. 1966. Effect of oilseeds food on the biology of Tribolium castaneum H., Trogoderma granarium Everts and Corcyra cephalonica (Stain.) and their susceptibility to pyrethrins. Ind. J. Ent. 28(2): 234-240.

Mbata, G.N. 1989. Studies on some aspects of the biology of Corcyra cephalonica (Stain.). Rev. Appl. Ent. 78(7): 793.

Morrison, R. K., R. E. Stinner, and R. L. Ridgway. 1976. Mass production of Trichogramma pretiosum on eggs of the Angoumois grain moth. Southwestern Entomol. 2:74-80.

Muthukrishnan, N., M.S. Venugopal, K. Ilamurougu and R. Janarthanan. 1996. Recycling of spent larval food of Corcyra cephalonica for fuel gas production. Rev. Agril. Ent. 85(12): 1418 
Nicol, J.M. 1935. Notes on the Gallerid moth, Corcyra cephalonica (Stain.). Rev. Appl. Ent. 23(9): 502.

Ozpnar, A. 1997 Comparison of some biological parameters of Trichogramma evanescens Westwood on the eggs of Ephestia kuehniella Zeller and Sitotroga cerealella (Olivier). Bitki Koruma Bulteni. 37(1/2): 59-65.

Perveen, F. 2012. Sitotroga cerealella and Corcyra cephalonica.

www. iaees. org/ publications/ journals/-----/role -of - temperature - and - hosts - sit.

Ray, R. 1994. Life table and intrinsic rate of increase of Corcyra cephalonica (Stain.) on maize. Ent. Abst. 25(10): 95.

Seshagiri, A.D. 1954. Notes on rice moth, Corcyra cephalonica (Stain.). (Galleriidae: Lepidoptera) Indian J. Ent. 16(2): 95-114. 